\title{
Patient Comorbidities Increase Postoperative Resource Utilization After Laparoscopic and Open Cholecystectomy
}

\section{Citation}

Boehme, Jacqueline. 2016. Patient Comorbidities Increase Postoperative Resource Utilization After Laparoscopic and Open Cholecystectomy. Doctoral dissertation, Harvard Medical School.

\section{Permanent link}

http://nrs.harvard.edu/urn-3:HUL.InstRepos:27007733

\section{Terms of Use}

This article was downloaded from Harvard University's DASH repository, and is made available under the terms and conditions applicable to Other Posted Material, as set forth at http:// nrs.harvard.edu/urn-3:HUL.InstRepos:dash.current.terms-of-use\#LAA

\section{Share Your Story}

The Harvard community has made this article openly available.

Please share how this access benefits you. Submit a story.

\section{Accessibility}




\section{AbStract}

BACKGROUND: An understanding of the relationship between patient factors and healthcare resource utilization represents a major point of interest for optimizing clinical care and overall net savings, yet maintaining financial margins for provider revenues. This study aims to review resource utilization after cholecystectomy in order to characterize patient factors associated with increased postoperative ED visits and 30-day readmissions.

METHODS: 53,632 open and laparoscopic cholecystectomies were reviewed from July-2009 to December-2010 in a large private payer claims database. ICD-9 and CPT codes were available for each event, as well as basic demographics. Data regarding 30-day postoperative resource utilization metrics (emergency department visits and inpatient hospitalizations) were analyzed and stratified by key patient comorbidities. Differences between subgroups were evaluated with univariate and multivariable methods.

RESULTS: Of the 53,632 patients studied, $71.2 \%(38,171)$ were female and $28.8 \%(15,461)$ male. Resource utilization within 30-days of surgery included: 6.6\% $(3,538)$ of patients with an ED visit and $7.7 \%(4,103)$ with an inpatient hospitalization. The most common comorbidities in the study population were: hypertension, hyperlipidemia, GERD / hiatal hernia, and diabetes mellitus. Patients with heart failure, cirrhosis, and a history of MI or acute ischemic heart disease all had a significant association with postoperative ED visit and the highest likelihood of inpatient hospitalization. Angina, diabetes, and hypertension similarly increased both ED utilization and inpatient readmissions to a lesser but still significant extent. Although patients with GERD / hiatal hernia and sleep apnea had a significant association with ED use, they did not have an increased likelihood of readmission.

CONCLUSIONS: Patient comorbidity indexing plays a major role in clinical risk stratification and resource utilization for cholecystectomy. These factors should be considered in bundled reimbursement packages and in the creation of preventive postoperative ambulatory strategies given their role in determining potential resource utilization in the postoperative setting. 


\section{TABLE OF CONTENTS}

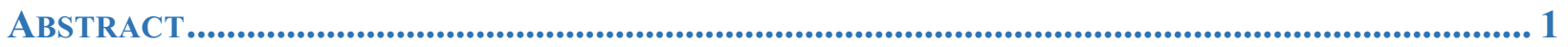

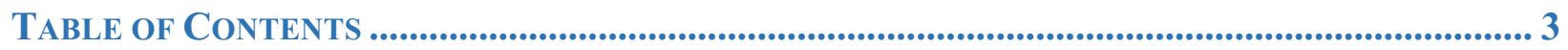

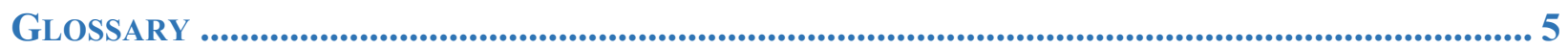

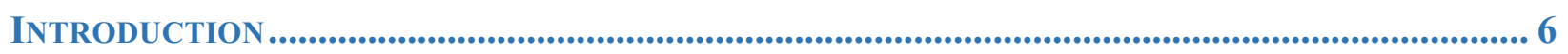

BACKGROUND: THE US OUTLIER AND THE AFFORDABLE CARE ACT ….............................................

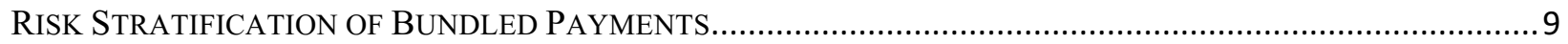

CASE: THE CHOLECYSTECTOMY AND CONTRIBUTORS TO RESOURCE USE ............................................. 10

METHODS........................................................................................................... 11

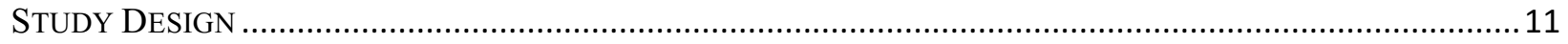

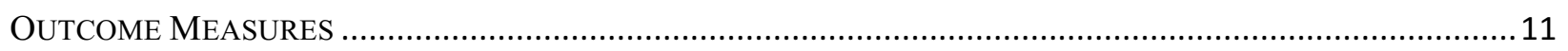

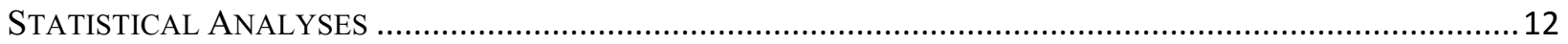

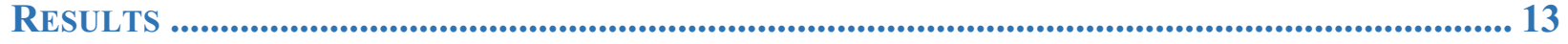

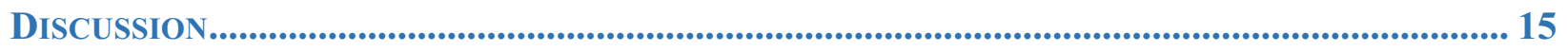

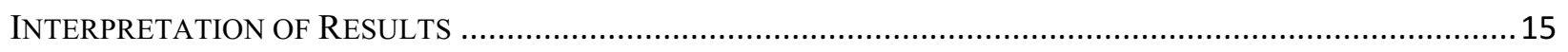

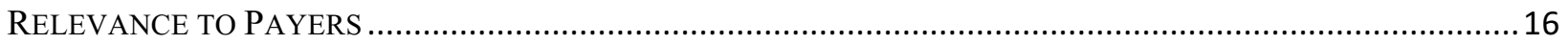

RELEVANCE TO PROVIDERS AND HOSPITAL ADMINISTRATORS.......................................................... 16

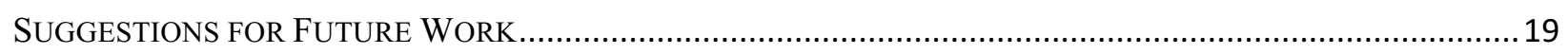

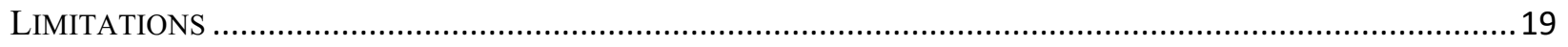

CONCLUSIONS................................................................................................................. 21

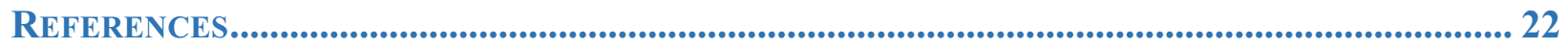

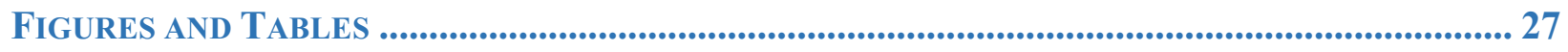

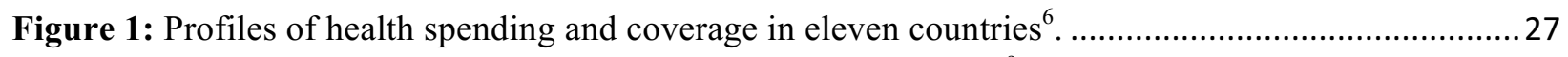

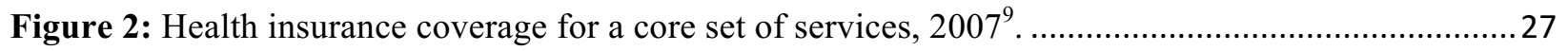

Figure 3: The relationship between life expectancy and health spending per person ${ }^{11}$..........................28

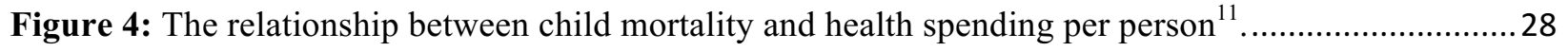

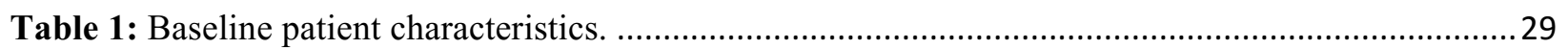

Table 2: Prevalence of comorbidities in the study population...........................................................29

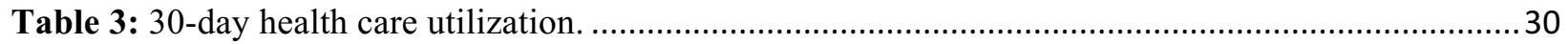

Table 4: ICD-9 codes and corresponding diagnoses for 30 -day readmissions. ......................................30

Table 5: Univariate analysis of 30 -day resource utilization stratified by sex........................................ 30

Table 6: Univariate analysis of 30-day resource utilization stratified by comorbidity............................30

Table 7: Multivariable odds ratios for 30 -day readmissions. ................................................................. 


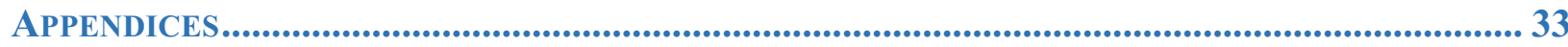

Appendix 1: ICD-9 codes and CPT codes used to identify cholecystectomy procedures.......................33

Appendix 2: Detailed univariate analysis of 30-day resource utilization stratified by sex.......................33

Appendix 3: Detailed univariate analysis of 30-day resource utilization stratified by comorbidity..........33

Appendix 4: Multivariable odds ratios for 30-day readmissions with same-day discharge. ....................37

Appendix 5: Multivariable odds ratios for 30 -day overnight readmissions. .............................................37 


\title{
GLOSSARY
}

\author{
ACA Affordable Care Act \\ ACO Accountable care organizations \\ BPCI Bundled Payments for Care Improvement \\ CCTP Community-based Care Transitions Program \\ CMS Centers for Medicare \& Medicaid Services \\ CPT Current Procedural Terminology \\ ED Emergency department \\ GDP Gross domestic product \\ GERD Gastroesophageal reflux disease \\ HIV/AIDS Human immunodeficiency virus / Acquired immunodeficiency syndrome \\ ICD-9 International Classification of Diseases, Ninth Revision \\ IHD Ischemic heart disease \\ IRB Institutional review board \\ JSH Joint replacement surgical home \\ LOS Length of stay \\ MI Myocardial infarction \\ MS-DRG Medicare Severity Diagnosis Related Group \\ NOS Not otherwise specified \\ OECD Organisation for Economic Co-operation and Development \\ OR Odds ratio \\ RUQ Right upper quadrant \\ THA Total hip arthroplasty \\ TKA Total knee arthroplasty \\ UC University of California \\ VNA Visiting Nurse Association \\ VBP Hospital Value-Based Purchasing Program \\ WWII World War II
}




\section{INTRODUCTION}

\section{Background: The US Outlier And THE AfFordable CARE ACT}

In mid-2007, the United States began to slip into the start of what was to become the worst financial crisis in the post World War II (WWII) era ${ }^{1}$; it was informally referred to as the Great Recession. The US gross domestic product (GDP) dropped a staggering $5.1 \%$ during the worst of it, from the fourth quarter of 2007 through the second quarter of 2009. Prior to this, the largest recorded drop in the post-WWII era had been just 3.7\% in $1957-1958^{2}$. Unemployment figures skyrocketed reflecting the 8.7-million jobs lost. Consumer spending and business investments plummeted as the US economy headed towards its worst nadir in modern history ${ }^{2,3}$.

Despite the recession and accompanying period of sluggish economic recovery through 2013, the United States spent an estimated \$2-3 trillion per year on health care, with expenditures rising annually. Through 2013, health care comprised an impressive $17.4 \%$ of the United States GDP ${ }^{4,5}$. This figure corroborates that the US spent more of its GDP on health care than any other country in the world. As evident in Figure 1 from Schoen et $\mathrm{al}^{6}$, the US devoted a $6 \%$ greater share of its economy on health than the Netherlands, the country with the second largest proportion of its GDP spent on health care.

Were health accessibility, affordability, and outcomes similar between the US and the other countries listed above, perhaps this number would not be so troubling; existing data, however, show that these exorbitant costs did not and still do not translate to better care.

\section{Accessibility}

Before the implementation of the Patient Protection and Affordable Care Act (ACA), $16 \%$ of the entire US population - consisting of approximately 50-million people - were completely uninsured. Moreover, millions of Americans remained underinsured, meaning they lost a significant portion of their income to health care costs not covered by insurance $^{6,7}$. In some states such as Nevada and Texas, the percentage of uninsured soared at an incredible $27 \%$ of the adult population ${ }^{8}$. This remains a stark contrast to the universal health coverage provided by our western counterparts in Europe, where the 
percentage of uninsured is virtually $0 \%$. Figure 2 from the Organisation for Economic Co-operation and Development (OECD)'s health indicators ${ }^{9}$ depicts the percentages of the population that were either insured (via public or private insurance) or uninsured across the various OECD participating countries in 2007.

\section{Affordability}

In the Schoen et al study ${ }^{6}$ previously mentioned that included ten of the world's major developed nations in addition to the US, adults in the US were more likely than adults in any other nation to have healthcare access issues related to cost. For example, they were the most likely to have not seen a doctor when ill or not get recommended care due to cost. They also did not fill their prescription medications and skipped medication doses 2.6 times as often as adults in the country second most likely to have done so, Canada. Finally, adults in the United States were more likely than adults in all other countries to have had $\$ 1,000$ or more out-of-pocket medical expenditures.

\section{Health Outcomes}

Life expectancy and child mortality: In 2007, life expectancy at birth in the US (78.1 years) was one year less than the OECD average (79.1 years) and approximately two years less than that of any western European nation. Although life expectancy in the US (78.8 years) increased slightly in 2013, it staggered and lingered almost one year behind the OECD average ( 80.5 years) and 2-4 years behind the life expectancy in western European nations ${ }^{9,10}$.

Low birth weight: The US had one of the incidence levels of low birth weight infants in 2007 , with $8.3 \%$ of infants born weighing less than 2,500g; the OECD average at the time was $6.8 \%$ of infants. Both incidence levels decreased in 2013, with the US at $8.0 \%$ of infants weighing less than $2,500 \mathrm{~g}$ at birth and the OECD average at $6.6 \%$ of infants ${ }^{9,10}$.

Prevalence and incidence of various illnesses: The estimated prevalence of diabetes in the US (10.3\%) ranked only second to Mexico (10.8\%) in 2010, and led the OECD average 
(6.3\%) by a full four percentage points. In 2006, the incidence of HIV/AIDS was highest in the US of all the OECD countries, at a stunning 127 new cases per million in the general population; OECD average was almost eight times less, at 16.2 new cases per million $^{9,10}$.

Mortality due to various illnesses: As compared to other western European nations, the US ranks highly in terms of death as a result of ischemic heart disease (IHD) although this number has decreased since 2006. Mortality rates due to all cancers and cerebrovascular disease were appreciably lower in the US than in other western nations in both the OECD's 2009 and 2015 reports ${ }^{9,10}$.

\section{Defining Value}

Figure 3 depicts the relationship between life expectancy and total health spending per person $^{11}$. The United States is shown on the far right-bottom with a high cost and low life expectancy, relative to the other countries shown. Similarly, Figure 4 demonstrates the association between child mortality and total health spending per person ${ }^{11}$. The US is shown on the far right-top with a high cost and high child mortality. Michael Porter from Harvard Business School defined value within health care delivery as the health outcomes achieved per dollar spent ${ }^{12}$. Given the low life expectancy and high child mortality rates despite the elevated cost of care, these data indicate that the value of health care in the US is inferior to that of much of the developed world.

In order to begin to address these overwhelming issues of poor access to health, inadequate insurance coverage, unsustainable costs, and the inferior value of health care in the US, the ACA was implemented in $2010^{13}$. The ACA created the structural foundation for interventions intended to increase insurability and contain healthcare costs. Examples of costcontainment programs included in the act were Community-based Care Transitions Program (CCTP) to decrease readmission rates, Hospital Value-Based Purchasing Program (VBP) to shift financial risk from Medicare to providers in order to transform incentives, and the Shared Savings Program to reward providers for reducing costs ${ }^{7}$. The scaffolding that the ACA provided 
laid the groundwork for the establishment of accountable care organizations (ACOs) and the widespread use of bundled payments. In 2011, the Centers for Medicare \& Medicaid Services (CMS) launched the Bundled Payments for Care Improvement (BPCI) initiative in accordance with Section 3023 of the ACA; this stated that Medicare bundled payments would be piloted in 2013. CMS commenced the application of cost savings paradigms via bundled payments when it announced the healthcare organizations selected to participate as ACOs in the BPCI in January of $2013^{14}$. Through these approaches, implementation of the ACA has slowly initiated a transformation in economic incentives that increase provider participation in order to achieve its goals of creating high value, affordable health care available to most ${ }^{15}$. Thus, the ACA triggered a closer look at healthcare spending with the aim to decrease inefficiencies, increase the quality of care that patients receive, and lower overall healthcare costs.

\section{Risk StRatification of Bundled PAYMENTS}

In order to account for fluctuations in costs per patient, the ACA called for a risk adjustment strategy. Accordingly, bundled payments in the ACA and BPCI initiative were founded in risk stratification based on the existing Medicare Severity Diagnosis Related Group (MS-DRG). The MS-DRG attaches significance to acute illnesses or acute decompensations of chronic illnesses ${ }^{16}$. Thence, bundled payments to ACOs were to include increased payments based on MS-DRG risk stratification to to compensate for the higher costs of treating more severely ill patients.

The higher cost of treating sicker patients does not solely correlate with the acute disease burden represented by the MS-DRG, however; chronic disease burden significantly impacts a patient's total cost of care and may in fact play a greater role in resource utilization than acute disease burden does. Vertrees et al found that a patient's chronic disease burden may in fact be more predictive of a patient's resource use than the acute disease burden ${ }^{16}$. Hughes et al showed the predictive power of integrating the chronic disease burden of patient comorbidities into a system of risk categories in order to stratify patients by their expected use of healthcare resources in a future year ${ }^{17}$. Therefore, although existing risk adjustment under the ACA was founded in the known effects of acute illness, chronic disease burden may also prove a significant target. 


\section{Case: The Cholecystectomy and Contributors to Resource Use}

Gallstone disease is the fourth most costly gastrointestinal disease in the United States; direct and indirect costs for care related to cholelithiasis totaled \$6.2-billion in $2004^{18}$. Not surprisingly, the cholecystectomy is the most common elective abdominal surgical procedure performed in the United States with more than 750,000 cases occurring each year ${ }^{19}$. Considering the factors that contribute to the estimated $\$ 15,651$ median cost per case $\mathrm{e}^{20}$, complications and comorbidities may play a significant role in the total cost of care. Injury to the common bile duct is well known as a major contributor to cost and resource utilization, with immediate associated costs ranging from $\$ 13,612$ to $\$ 30,000$ and lifetime costs reported as high as $\$ 300,000^{21-24}$. In addition, various patient, hospital, and surgeon factors - such as age, sex, presence of comorbidities, urgency of admission and surgery, length of stay (LOS), treatment in a regional or district hospital, hospital volume, and surgeon experience ${ }^{25-32}$ - have been shown to affect cholecystectomy outcomes and associated overall resource use and costs.

As previously mentioned, chronic disease burden has been shown to be more predictive of patient cost and resource use than acute illness ${ }^{16,17}$. Prior studies have also evinced the influence of patient comorbidities on the utilization of resources such as office visits, emergency department (ED) visits, length of stay, drug costs, procedures, and overall costs in other study populations $^{33-37}$.

Given the significance of chronic illness burden and the knowledge of how patient factors influence resource utilization in other conditions, this study serves to elucidate the impact of specific patient comorbidities on resource utilization after cholecystectomy. In the context of our current healthcare system's movement towards innovative reimbursement models, quantification of these impacts may be useful to payers for guiding the development of risk-stratified, case-mix appropriate bundled reimbursement packages to providers for cholecystectomies. Furthermore, this information may be useful to providers in order to create strategies to prevent excess resource utilization, thereby decreasing inefficiencies, increasing the value of care for patients, and simultaneously creating profit margins under the ACA's Shared Savings Program. 


\section{Methods}

This was a retrospective observational cohort study of privately insured patients undergoing cholecystectomy in which predictor variables were defined by the presence or absence of various chronic comorbid conditions. Approval from the Cambridge Health Alliance institutional review board (IRB) was obtained.

\section{STUDY DESIGN}

This study was a retrospective cohort study utilizing a private payer claims database (Aetna, Inc., Hartford, CT). Inclusion criteria consisted of age $\geq 16$ years, a record of cholecystectomy between July 1, 2009 and December 31, 2010, and enrollment in the health plan for at least 6 months before and 3 months after the cholecystectomy to stabilize the co-morbidity database and allow tracking of consecutive health events and resource use. Claims records were stripped of protected health information by Aetna personnel not involved in this study to produce the HIPAA-compliant de-identified dataset used in this analysis. Cholecystectomy procedures were identified by the International Classification of Diseases, Ninth Revision (ICD-9) or Current Procedural Terminology (CPT) codes listed in the appendix.

\section{Outcome Measures}

Data regarding 30-day postoperative resource utilization were stratified and analyzed by patient comorbidities. The comorbid conditions that were studied include hypertension, hyperlipidemia, gastroesophageal reflux disease (GERD) / hiatal hernia, diabetes mellitus, angina / chronic IHD, sleep apnea, heart failure, myocardial infarction (MI) / acute IHD, hypertensive heart disease, and cirrhosis of the liver or bile ducts. These conditions were defined by the presence of an associated ICD-9 code within the 6-month period immediately prior to the cholecystectomy.

The endpoints in this study were 30-day ED visits, 30-day readmissions, and length of stay for the 30-day readmissions. A readmission was defined as utilization classified as inpatient in the source data. Length of stay was calculated as discharge date minus admission date. 


\section{StATisticAl ANALYSES}

Descriptive statistics were used to summarize baseline patient characteristics, including demographics and comorbid conditions. Outcomes were summarized for the overall population and by subgroups with and without each comorbid condition. Pearson's chi-squared p-values were calculated to evaluate the statistical significance of all differences in outcomes between cohorts. No adjustments were made to these p-values to account for multiple comparisons.

Logistic regression was utilized to determine the impact of baseline comorbid conditions on 30-day readmission rates, while adjusting for demographic differences. Stepwise selection was used to choose the statistically significant predictor variables from among all studied comorbid conditions, age, gender, and region. Sensitivity regression models were also run for the subsets of readmissions including and not including an overnight stay. All statistical analyses were conducted using SAS Version 9.2 (SAS Institute, Cary, North Carolina). 


\section{RESULTS}

A total of 53,632 patients was included in this study; $71.2 \%(38,171)$ were female, $28.8 \%$ $(15,461)$ male. Baseline patient characteristics are shown in Table 1. Of all cholecystectomies studied, 94.9\% (50,900) were laparoscopic, 63.9\% (34,285) were outpatient procedures, and $51.2 \%(27,439)$ occurred in the South (US Census Region 3) of the United States. The prevalence of chronic comorbidities seen in the study population are reported in Table 2. Hypertension, hyperlipidemia, GERD / hiatal hernia, and diabetes mellitus were the most prevalent of the comorbid conditions studied, at 34.2\% (18,324), 30.7\% $(16,436), 25.1 \%$ $(13,465)$, and $13.7 \%(7,354)$ in the study population, respectively.

Within 30-days of surgery, $6.6 \%(3,538)$ of patients returned to the ED a total of 4,523 times. This led to an average of 1.3 ED visits per patient visiting the ED and an average of 0.1 ED visits for the entire cohort. Additionally, 7.7\% (4,103) of patients had inpatient readmissions within 30-days of their procedure. Of all patients with 30-day inpatient readmissions, 60.0\% $(2,461)$ had a LOS of 0 days ${ }^{*}, 16.5 \%$ (677) 1-2 days, $14.2 \%$ (583) 3-5 days, $5.2 \%$ (214) 6-10 days, and 4.1\% (168) 11 days or longer. (Table 3) The top three diagnoses recorded during the inpatient readmissions were abdominal pain at an unspecified site, chest pain not otherwise specified (NOS), and abdominal pain in the right upper quadrant (RUQ) at 7.6\% (700), 2.4\% (223), and 2.4\% (217), respectively (Table 4).

ED visits were not significantly different across sexes but inpatient hospitalizations were, with males comprising a greater proportion of readmitted patients $(9.9 \%$ males versus $6.8 \%$ females, $\mathrm{p}<0.0001$ ) (Table 5). Resource utilization within 30-days of cholecystectomy, stratified by comorbid conditions, is shown in Table 6. All of the comorbidities studied, except for hyperlipidemia and hypertensive heart disease, had a significantly increased postoperative ED utilization.

Odds ratios and 95\% Wald confidence limits for the effect of baseline comorbidities on 30-day readmission are shown in Table 7. All studied comorbid conditions except GERD and

\footnotetext{
${ }^{*}$ Lengths of stay were calculated by subtracting discharge date from admission date. LOS of 0-days informs that the admission and discharge date were the same, suggesting discharge from the hospital before midnight on the same day as admission.
} 
sleep apnea were statistically significant predictors of 30-day readmission. Of the remaining baseline comorbidities, all resulted in increased risk of readmission except for hyperlipidemia, which showed a slightly reduced risk after adjusting for all other predictors [Odds Ratio $(\mathrm{OR})=0.867, \mathrm{CI}: 0.801-0.938, \mathrm{p}=0.0004]$. Comorbid conditions that significantly increased the odds of a 30-day readmission included both acute and chronic IHD, cirrhosis of the liver or bile ducts, diabetes, heart failure, hypertension, and hypertensive heart disease. Age also had a highly significant impact on 30-day readmission, with OR estimates increasing from 0.993 for ages 3544 to 4.277 for ages 75 and older. Gender and region had modest but statistically significant impacts on 30-day readmission, with females at lower risk than males and patients in the South having the lowest regional risk compared to patients in the Midwest with the highest risk of readmission. 


\section{DISCUSSION}

\section{INTERPRETATION OF RESULTS}

The relationship between chronic patient comorbidities and postoperative resource use after cholecystectomy has been poorly defined in the literature. Some reports relating comorbidities and/or complications to cost exist ${ }^{20,21,25,26}$, but a greater understanding of chronic disease burden on the utilization of specific resources is needed to guide both economic policy and clinical decision-making. This paper is intended to define the relationship that exists between patient comorbidities and postoperative utilization of resources in terms of distinct visits after laparoscopic and open cholecystectomy.

In this study, patients with heart failure were the most likely of all to visit to the ED and to be readmitted; in fact, these patients are 2.1 times more likely than healthy patients to be readmitted within 30-days of their cholecystectomy. Patients with either cirrhosis or a history of acute IHD also had significant association with postoperative ED visit and were 1.5-1.6 times as likely to have an inpatient readmission. Those with chronic IHD, diabetes mellitus, and hypertension had a significant association with ED visit and also had a modestly increased likelihood of inpatient readmission that was 1.2-1.3 times that of their healthy counterparts.

Forty-six percent of cholecystectomy costs are attributable to room and board ${ }^{20}$. Therefore, it is prudent to note the influence of the comorbidities that increase readmission rates and inpatient LOS after cholecystectomy in addition to those that increase ED utilization. Hyperlipidemia did not increase ED utilization and was a negative predictor of inpatient readmissions in this study population. This may reflect a population of otherwise healthy patients presenting with a 'laboratory comorbidity' as defined by strict numbers yet without any type of actual visceral organ disease.

These data demonstrate how two patients with similar costs but different chronic conditions lead to different utilization of resources after surgery: a patient with GERD who visits the ED repeatedly for reflux symptoms and pain in the postoperative setting versus a patient with cirrhosis and heart failure requiring a prolonged inpatient hospitalization postoperatively due to fluid shifts and heart failure exacerbation after intraoperative fluid resuscitation. Although these 
patients may be very similar in a strictly monetary sense, their use of hospital resources is vastly different. These insights will prove extremely valuable for applying paradigms for care coordination and cost savings under the ACA.

\section{RELEVANCE TO PAYERS}

An understanding of the specifics of resource utilization by patient comorbidity will first allow for appropriate departmental reimbursements by insurance companies. In this analysis, not every comorbidity that increased utilization of ED resources led to increased readmission rates. The two comorbidities that were associated with an increased likelihood of ED visit that did not lead to inpatient readmissions were GERD / hiatal hernia and sleep apnea. Similarly, the impact of resource use will vary from organization to organization based upon the characteristics of their patient population.

Second, an understanding of the impact of each comorbidity from this paper can form the foundation for the risk adjustment of bundled payments for cholecystectomies based on a particular healthcare system's chronic illness trends in their patient population. Calculations for bundled payments would be based on the likelihood of the various types of visits and LOS for inpatient readmissions.

\section{Relevance to Providers And Hospital Administrators}

Past successes in bundled payment models exist, a prime example of which is Geisinger Health System's ProvenCare initiative for coronary artery bypass grafting ${ }^{38}$. However, reimbursements for surgical procedures are decreasing in the face of increasing productivity and governmental regulations. Over the past 15 years, reimbursement has decreased by $2.9 \%$ for cholecystectomies $^{39}$. At present-day Medicaid reimbursement rates, Frazee et al's analysis ${ }^{40}$ defines the 'break-even point' for laparoscopic cholecystectomy at 454 cases - this presents a major financial limitation to lower-volume centers performing this operation and therefore may negatively impact access to care. Analysis of the comorbid conditions in a particular healthcare group's coverage will aid in the projection of resource utilization and subsequent administrative planning for cholecystectomy. Such preparation will enable various processes: Opportunities for 
the creation of preventive strategies, optimization of healthcare delivery, and appropriate distribution of reimbursement profiles to enable increased profit margins for providers, in the context of the risk-adjusted reimbursements from payers mentioned above.

From the clinician perspective, the knowledge gained from this study will be used to guide strategies to optimize patients in the perioperative period and consequently, decrease postoperative resource utilization. Strategically preventing exacerbation of existing patient comorbidities in the perioperative setting represents one of the major goals of the BPCI and is currently a hot topic in the surgical care realm. To undertake this daunting task, administrators, physicians, and ancillary staff have come together in the few years since the implementation of the ACA to create the perioperative surgical home (PSH) model of care ${ }^{41}$.

A mélange of evidence-based practices from lean six sigma theory and its predecessor, Enhanced Recovery After Surgery (ERAS) ${ }^{41}$, the PSH model of care has already been shown to minimize postoperative resource utilization and costs. In 2012, University of California (UC) Irvine implemented the patient-centered and physician-driven PSH model of care when it initiated its total knee arthroplasty (TKA) and total hip arthroplasty (THA) programs; a followup study in two years after the commencement of both programs compared its costs to those in the reported literature. Costs for UC Irvine's TKAs were, on average, $\$ 6,000-\$ 8,000$ less than the benchmark comparison ${ }^{42}$ and its THAs were approximately $\$ 5,000-\$ 8,000$ less $^{43}$.

Under the PSH model of care, interventions are targeted at various levels of patient care the preoperative, intraoperative, and postoperative periods ${ }^{41}$. Innovative examples of cost saving strategies specific to patient comorbidities at each level of care might include the following.

\section{Preoperative Period}

Physicians could coordinate close follow-up in the 1-2 weeks prior to surgery for patients most likely to be readmitted. Such care could include weekly in-office visits or frequent phone calls with ancillary medical staff for careful titration of medications aimed at optimizing the patient's physiologic balance before surgery. 


\section{Intraoperative Period}

During the intraoperative period, anesthesiologists must maintain equilibrium despite often opposing physiologic and surgical needs, with the added burden of chronic illness. If a patient is afflicted with a comorbid condition that significantly increases their likelihood of readmission such as heart failure in this study's dataset, the anesthesiologist could consider immediate preoperative evaluation in the holding area with a bedside pulmonary and/or transthoracic ultrasound. This cheap and quick bedside examination could provide valuable information regarding the patient's cardiac function and overall volume status via the presence of pathology such as pulmonary edema, pleural effusions, and inferior vena cava variability ${ }^{44}$. The anesthesiologist could then use this information to guide a restrictive or liberal volume resuscitation protocol intraoperatively, depending on other surgical factors as well.

\section{Postoperative Period}

In addition to the existing foundations for surgical recovery laid out by ERAS, clinicians could coordinate close follow-up care targeted at preventing exacerbations of chronic conditions for the patients statistically most likely to return to the hospital based on their disease states. Perioperative care physicians could coordinate follow-up telephone calls, home ambulatory services such as Visiting Nurse Association (VNA) visits, and outpatient follow-up with primary care providers. Without the added assurance of inhouse hospital monitoring, the postoperative period provides a unique environment in which the use of innovative technology could have great potential. Mobile health technologies could be provided to the highest-risk patients for real-time monitoring by third-party agencies and reporting to ancillary staff for health optimization. This novel application of technology could prevent chronic health exacerbations at the first sign of pathology, before symptoms ever developed and well before patients visited the ED or were readmitted. Devices could include smart watches for heart rate monitoring, at-home scales and sphygmomanometers with real-time data transmission, and more. 
These services could not only lead to less ED visits and inpatient hospitalizations, but also result in better coordination of care, create greater value of services received for patients, and yield lower overall costs to the healthcare system. Although a study using aggregates of comorbidity information could have led to similar findings in terms of identifying trends in resource utilization with increasing chronic disease burden, aggregate patient data would not have allowed for the specific information provided by this study's data to create targeted prevention strategies for individual comorbidities.

The knowledge gained from this study can be used to: (1) Influence payers to create evidence-based payment models with global reimbursements focused on clearly defined packages of patient-centered and risk-stratified post-discharge resources in the postoperative setting after cholecystectomy; and (2) Guide providers to create targeted cost saving interventions in the pre-, intra-, and post- operative periods aimed at decreasing resource utilization for patients in the highest risk groups.

\section{SugGestions For Future WorK}

Although the prevention strategies mentioned are certainly possible for reducing postoperative resource utilization, an understanding of the cause of these readmissions must first be established. Suggestions for future work include root cause analyses to determine the factors contributing to ED visits and readmissions in the postoperative setting for the comorbidities mentioned in this study. Additional work thereafter could include application of tactics targeted at these causes and an analysis of the impact of such interventions.

\section{LIMITATIONS}

Despite the advantages of using a large private payer database for studying postoperative resource utilization after cholecystectomy, there are several limitations to this approach. The major limitations relate to the use of claims data, namely that we must use ICD-9 diagnosis codes to determine patient comorbid conditions and that the study population is not nationally representative. The data source used in this study only included subscribers to a single private insurance provider and did not include the uninsured population. Using ICD-9 codes to 
determine comorbidities can lead to under-representation of the conditions in the study population, though coding of chronic conditions tends to be much more complete at the time of hospitalization and/or surgical intervention. Although the comprehensive nature of patient utilization captured in claims data is helpful for elucidating 30-day postoperative resource utilization, it likely overestimates the use of resources associated with cholecystectomy, as the etiology of the visit or hospitalization could be another, unrelated source.

Obesity is known to both correlate with and contribute to the pathophysiology of many of the conditions associated with increased utilization of resources in this study, such as hypertension, hyperlipidemia, GERD and hiatal hernia, diabetes mellitus, heart disease, sleep apnea, and heart failure ${ }^{45}$. The multivariate analyses we conducted allowed for the evaluation of each risk factor independently of the other but did not allow for the evaluation of the effects of obesity, a variable excluded from the study due to severe under-reporting of obesity codes. Martin et al's Canadian study ${ }^{46}$ revealed that a diagnosis of obesity had a sensitivity of a mere $7.75 \%$ in their database of 17,380 patients; similarly Januel et $\mathrm{al}^{47}$ show the scanty sensitivity of obesity coding in Switzerland (ranging from 29.4\% in 1999 to $51.5 \%$ in 2003). These studies convey the extent to which obesity is under-reported in administrative databases. Therefore, it was not possible to determine the resultant effect of obesity on postoperative resource utilization in this study. In accordance with the ACA mandate that healthcare claims data be used extensively to assess resource utilization and quality of care starting in $2015^{13}$, it is inevitable that large payer and other administrative databases will be increasingly used to evaluate healthcare systems in the near future. In order for authorities involved in all aspects of healthcare to draw accurate conclusions from these databases, more precise coding information regarding obesity needs to be included.

Finally, Rao et al demonstrated that dialysis-dependent patients with end-stage renal disease had an increased risk of a number of postoperative complications after laparoscopic cholecystectomy which led to increased mean length of stay in the hospital ${ }^{48}$. Due to the low number of patients with renal failure in the study cohort, however, this condition was not included in the analysis. 


\section{CONCLUSIONS}

This study showed that certain comorbid conditions significantly increase utilization of postoperative resources in terms of ED visits and inpatient readmissions. In particular, heart failure, cirrhosis, and a history of MI / acute ischemic heart disease were not only significantly associated with increased ED utilization but also had the highest likelihood of inpatient readmission. Further investigation may identify the causality of these relationships and lead to the development of preventive strategies. Such an approach has the potential to not only decrease unnecessary visits, but also improve the quality of patient care and maintain provider profit margins in the face of decreasing reimbursements for surgical procedures. These factors should be considered in bundled reimbursement packages given their role in determining potential resource utilization in the postoperative setting.

A report of this work has been previously published (Boehme et al, 2015) ${ }^{49}$. 


\section{REFERENCES}

1. Bernanke, B. S. Monetary Policy and the Housing Bubble. in Annual Meeting of the American Economic Association 1-36 (2010).

2. Kowalski, A. Recession Took Bigger Bite Out of U.S. Economy Than Estimated. Bloomberg Business http://www.bloomberg.com/news/articles/2011-07-29/ (2011). at $<$ http://www.bloomberg.com/news/articles/2011-07-29/recession-took-bigger-bite-out-ofu-s-economy-than-previously-estimated>

3. Hugie Barello, S. Consumer spending and U.S. employment from the 2007-2009 recession through 2022. United States Dep. Labor Mon. Labor Rev. 1-38 (2014).

4. Keehan, S. P. et al. National Health Expenditure Projections, 2014-24: Spending Growth Faster Than Recent Trends. Health Aff. 34, 1407-1417 (2015).

5. Cuckler, G. A. et al. National Health Expenditure Projections, 2012-22: Slow Growth Until Coverage Expands And Economy Improves. Health Aff. 32, 1820-1831 (2013).

6. Schoen, C., Osborn, R., Squires, D. \& Doty, M. M. Access, Affordability, And Insurance Complexity Are Often Worse In The United States Compared To Ten Other Countries. Health Aff. 32, 2205-2215 (2013).

7. Hall, M. A. \& Lord, R. Obamacare: what the Affordable Care Act means for patients and physicians. Bmj 349, g5376-g5376 (2014).

8. Mangan, D. Top States: Big differences in health 'uninsured' rate. CNBC (2014).

9. Unit, P. E. \& Health, Q. Health at a Glance 2009. 90401, (OECD Publishing, 2009).

10. Health at a Glance 2015. (OECD Publishing, 2015). doi:10.1787/health_glance-2015-en

11. Gapminder: A Fact-Based Worldview. at

$<$ http://www.gapminder.org/world/\#\$majorMode=chart\$is;shi=t;ly=2003;lb=f;il=t;fs=11;a $\mathrm{l}=30 ; \mathrm{stl}=\mathrm{t} ; \mathrm{st}=\mathrm{t} ; \mathrm{nsl}=\mathrm{t} ; \mathrm{se}=\mathrm{t} \$ \mathrm{wst} ; \mathrm{tts}=\mathrm{C} \$ \mathrm{ts} ; \mathrm{sp}=5.59290322580644 ; \mathrm{ti}=2015 \$ \mathrm{zpv} ; \mathrm{v}=0$ \$inc $\_\mathrm{x} ; \mathrm{m}$ mid=XCOORDS;iid=phAwcNAVuyjljiMAkmq1iMg;by=ind\$inc_y;mmid=YCOORDS;i $\mathrm{id}=0$ ArfEDsV3bBwCcGhBd2>

12. Porter, M. E. Redefining health care: creating value-based competition on results. 
(Harvard Business School Press, 2006).

13. Patient Protection and Affordable Care Act. H.R. 3590(111) at $<$ http://thomas.loc.gov/cgibin/query/z?c111:H.R.3590.pp:>

14. Centers for Medicare \& Medicaid Services. Bundled Payments for Care Improvement Initiative Fact Sheet. (2014). at

$<$ http://www.cms.gov/Newsroom/MediaReleaseDatabase/Fact-sheets/2014-Fact-sheetsitems/2014-07-31.html>

15. Trends in Health Care Cost Growth and the Role of the Affordable Care Act. (2013). at $<$ http://whitehouse.gov/sites/default/files/docs/healthcostreport_final_noembargo_v2.pdf $>$

16. Vertrees, J. C., Averill, R. F., Eisenhandler, J., Quain, A. \& Switalski, J. Bundling PostAcute Care Services into MS-DRG Payments. Medicare Medicaid Res. Rev. 3, 1-19 (2013).

17. Hughes, J. S. et al. Clinical Risk Groups (CRGs): a classification system for risk-adjusted capitation-based payment and health care management. Med. Care 42, 81-90 (2004).

18. Everhart, J. E. \& Ruhl, C. E. Burden of digestive diseases in the United States part I: overall and upper gastrointestinal diseases. Gastroenterology 136, 376-86 (2009).

19. Flum, D. R., Dellinger, E. P., Cheadle, A., Chan, L. \& Koepsell, T. Intraoperative cholangiography and risk of common bile duct injury during cholecystectomy. Jama 289, 1639-44 (2003).

20. Stey, A. M. et al. Hospital Costs by Cost Center of Inpatient Hospitalization for Medicare Patients Undergoing Major Abdominal Surgery. J. Am. Coll. Surg. (2014). doi:10.1016/j.jamcollsurg.2014.10.021

21. Woods, M. S. Estimated costs of biliary tract complications in laparoscopic cholecystectomy based upon Medicare cost/charge ratios. A case-control study. Surg. Endosc. 10, 1004-7 (1996).

22. Phillips, E. H. Routine versus selective intraoperative cholangiography. Am. J. Surg. 165, 505-7 (1993).

23. Livingston, E. H., Miller, J. A. G., Coan, B. \& Rege, R. V. Costs and utilization of 
intraoperative cholangiography. J. Gastrointest. Surg. 11, 1162-7 (2007).

24. Flum, D. R., Flowers, C. \& Veenstra, D. L. A cost-effectiveness analysis of intraoperative cholangiography in the prevention of bile duct injury during laparoscopic cholecystectomy. J. Am. Coll. Surg. 196, 385-93 (2003).

25. Shi, H.-Y., Lee, K.-T., Uen, Y.-H., Chiu, C.-C. \& Lee, H.-H. Changing approaches to cholecystectomy in elderly patients: a 10-year retrospective study in Taiwan. World J. Surg. 34, 2922-31 (2010).

26. Zacks, S. L., Sandler, R. S., Rutledge, R. \& Brown, R. S. A population-based cohort study comparing laparoscopic cholecystectomy and open cholecystectomy. Am. J.

Gastroenterol. 97, 334-40 (2002).

27. Chen, S. L., Comstock, M. C. \& Taheri, P. A. The added cost of urgent cholecystectomy to health systems. J. Am. Coll. Surg. 197, 16-21 (2003).

28. Schwaitzberg, S. D. et al. Threefold increased bile duct injury rate is associated with less surgeon experience in an insurance claims database : More rigorous training in biliary surgery may be needed. Surg. Endosc. (2014). doi:10.1007/s00464-014-3580-0

29. Shi, H.-Y., Lee, K.-T., Chiu, C.-C. \& Lee, H.-H. The volume-outcome relationship in laparoscopic cholecystectomy: a population-based study using propensity score matching. Surg. Endosc. 27, 3139-45 (2013).

30. Lee, K.-T., Chang, W.-T., Huang, M.-C. \& Chiu, H.-C. Influence of surgeon volume on clinical and economic outcomes of laparoscopic cholecystectomy. Dig. Surg. 21, 406-12 (2004).

31. Harrison, E. M. et al. Hospital volume and patient outcomes after cholecystectomy in Scotland : retrospective, national. Br. Med. J. 344, 1-14 (2012).

32. Sinha, S. et al. Epidemiological study of provision of cholecystectomy in England from 2000 to 2009: retrospective analysis of Hospital Episode Statistics. Surg. Endosc. 27, 16275 (2013).

33. Margolis, J. M. et al. Health care utilization and expenditures among Medicaid beneficiaries with neuropathic pain following spinal cord injury. J. Pain Res. 7, 379-87 (2014). 
34. Carmona, M. et al. Heart failure in primary care: co-morbidity and utilization of health care resources. Fam. Pract. 30, 520-4 (2013).

35. D’Apuzzo, M. R., Novicoff, W. M. \& Browne, J. A. The John Insall Award: Morbid Obesity Independently Impacts Complications, Mortality, and Resource Use After TKA. Clin. Orthop. Relat. Res. 473, 57-63 (2015).

36. Shi, H.-Y. et al. Trends and outcome predictors after traumatic brain injury surgery: a nationwide population-based study in Taiwan. J. Neurosurg. 121, 1323-30 (2014).

37. Genther, D. J. \& Gourin, C. G. Effect of comorbidity on short-term outcomes and cost of care after head and neck cancer surgery in the elderly. Head Neck (2014). doi:10.1002/hed.23651

38. Casale, A. S. et al. 'ProvenCareSM': a provider-driven pay-for-performance program for acute episodic cardiac surgical care. Ann. Surg. 246, 613-21; discussion 621-3 (2007).

39. Hoballah, J. J., Liao, J., Salameh, M. \& Weigel, R. J. Physician Reimbursement for General Surgical Procedures in the Last Century: 1906-2006. J. Am. Coll. Surg. 206, 670677 (2008).

40. Frazee, R. C. et al. Can laparoscopic cholecystectomy be performed with a positive margin at medicaid reimbursement rates? J. Am. Coll. Surg. 218, 546-51 (2014).

41. Desebbe, O., Lanz, T., Kain, Z. \& Cannesson, M. The perioperative surgical home: An innovative, patient-centred and cost-effective perioperative care model. Anaesth. Crit. Care Pain Med. 1-8 (2015). doi:10.1016/j.accpm.2015.08.001

42. Kozma, C. M., Slaton, T., Paris, A. \& Edgell, E. T. Cost and utilization of healthcare services for hip and knee replacement. J. Med. Econ. 16, 888-96 (2013).

43. Raphael, D. R. et al. Total joint Perioperative Surgical Home: an observational financial review. Perioper. Med. (London, England) 3, 6 (2014).

44. Touw, H. R. W., Tuinman, P. R., Gelissen, H. P. M. M., Lust, E. \& Elbers, P. W. G. Lung ultrasound: routine practice for the next generation of internists. Neth. J. Med. 73, 100-7 (2015).

45. Skolnik, N. S. \& Ryan, D. H. Pathophysiology, epidemiology, and assessment of obesity 
in adults. J. Fam. Pract. 63, S3-S10 (2014).

46. Martin, B.-J., Chen, G., Graham, M. \& Quan, H. Coding of obesity in administrative hospital discharge abstract data: accuracy and impact for future research studies. $B M C$ Health Serv. Res. 14, 70 (2014).

47. Januel, J. et al. Improved accuracy of co-morbidity coding over time after the introduction of ICD-10 administrative data. BMC Health Serv. Res. 11, 194 (2011).

48. Rao, a. et al. Safety of elective laparoscopic cholecystectomy in patients on dialysis: An analysis of the ACS NSQIP database. Surg. Endosc. Other Interv. Tech. 28, 2208-2212 (2014).

49. Boehme, J. et al. Patient comorbidities increase postoperative resource utilization after laparoscopic and open cholecystectomy. Surg. Endosc. (2015). doi:10.1007/s00464-0154481-6 


\section{FIGURES AND TABLES}

Figure 1: Profiles of health spending and coverage in eleven countries ${ }^{6}$.

\begin{tabular}{lccc}
\hline & \multicolumn{2}{c}{ Health spending, 2011} & \\
& Per capita, USD & $\%$ GDP & Deductible \\
\hline United States & $\$ 8,508$ & $17.7 \%$ & Yes, no limit \\
Netherlands & $\$ 5,099$ & $11.9 \%$ & $\$ 460$ \\
France & $\$ 4,118$ & $11.6 \%$ & No \\
Germany & $\$ 4,495$ & $11.3 \%$ & No \\
Canada & $\$ 4,522$ & $11.2 \%$ & No \\
Switzerland & $\$ 5,643$ & $11.0 \%$ & $\$ 319-2,655$ \\
New Zealand & $\$ 3,182$ & $10.3 \%$ & No \\
Sweden & $\$ 3,925$ & $9.5 \%$ & No \\
United Kingdom & $\$ 3,405$ & $9.4 \%$ & No \\
Norway & $\$ 5,669$ & $9.3 \%$ & No \\
Australia & $\$ 3,800$ & $8.9 \%$ & No
\end{tabular}

Figure 2: Health insurance coverage for a core set of services, $2007^{9}$.

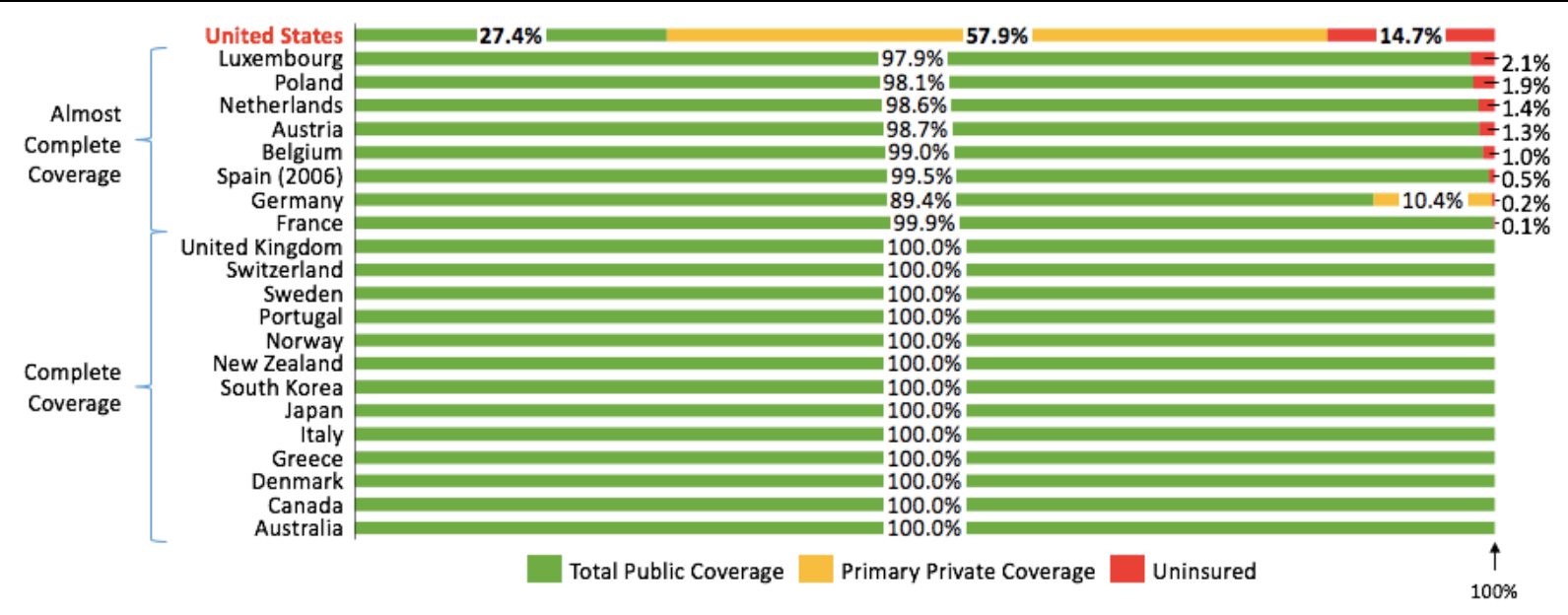


Figure 3: The relationship between life expectancy and health spending per person ${ }^{11}$.

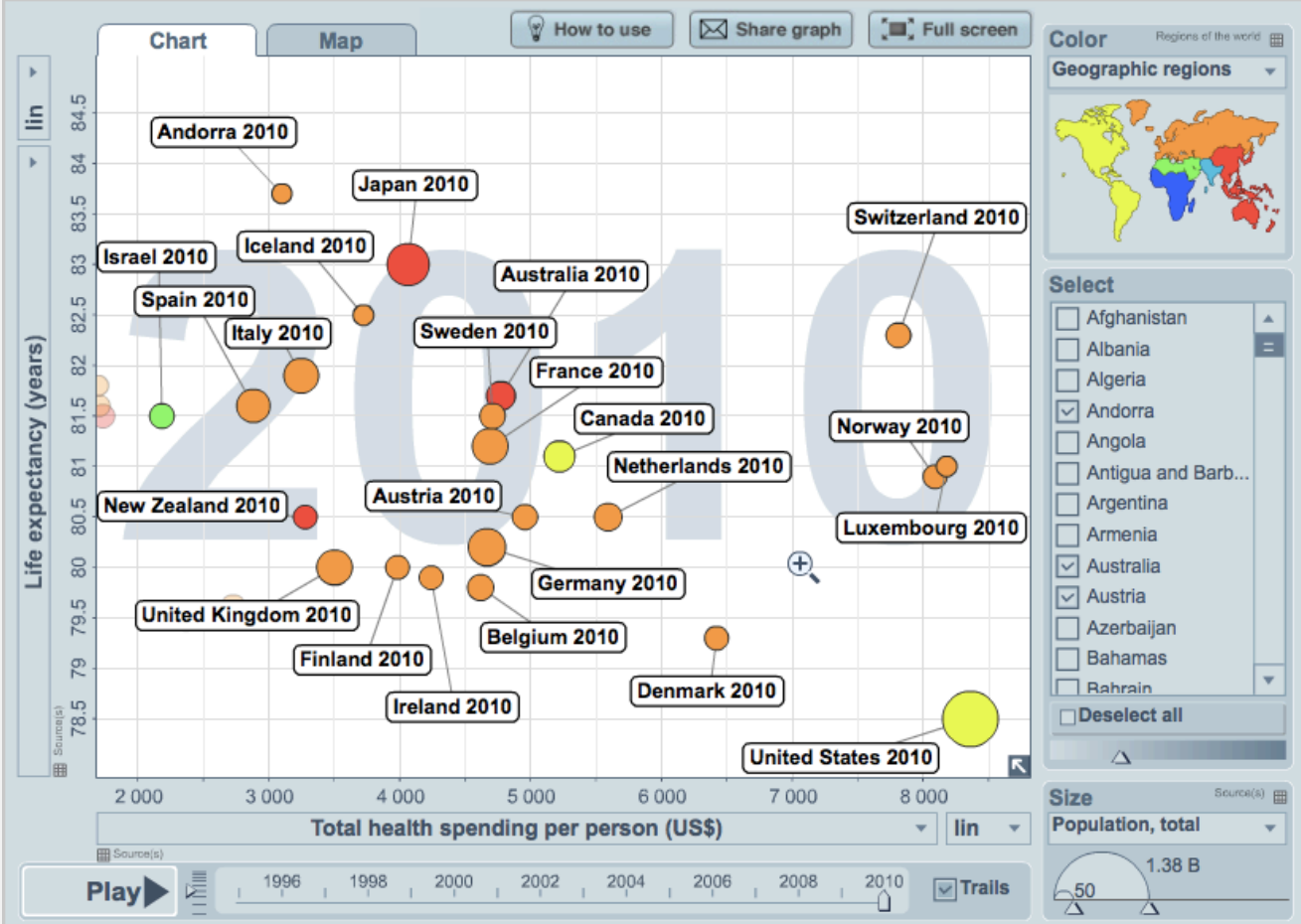

Figure 4: The relationship between child mortality and health spending per person ${ }^{11}$.

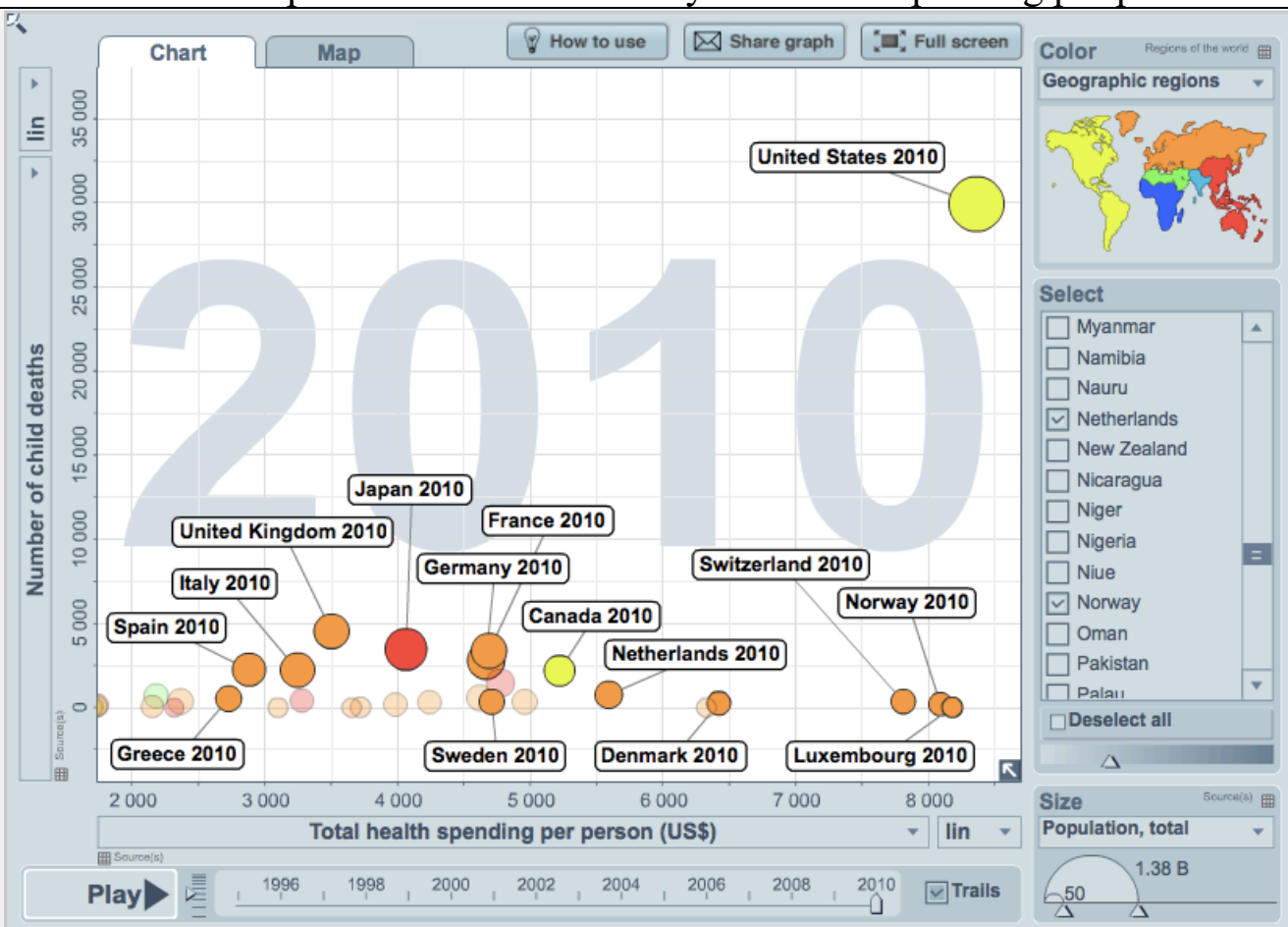


Table 1: Baseline patient characteristics.

\begin{tabular}{lcc}
\hline Variable & $\mathbf{n}$ & \% \\
\hline Sex & & \\
Female & 38,171 & 71.2 \\
Male & 15,461 & 28.8 \\
Age mean \pm SD (range) & $48.7 \pm 15.6(16-99)$ & \\
Age group, years & & \\
$<25$ & 3015 & 5.6 \\
$25-<35$ & 8275 & 15.4 \\
$35-<45$ & 11,400 & 21.3 \\
$45-<55$ & 12,676 & 23.6 \\
$55-<65$ & 10,678 & 19.9 \\
$65-<75$ & 4,283 & 8.0 \\
$75+$ & 3,305 & 6.2 \\
Region of country & & \\
Northeast & 9,715 & 18.1 \\
Midwest & 8,906 & 16.6 \\
South & 27,439 & 51.2 \\
West & 7,528 & 14.0 \\
Unknown & 44 & 0.1 \\
Type of surgery & & \\
Laparoscopic & 50,900 & 94.9 \\
Open & 2,161 & 4.0 \\
Unknown/conversion* & 571 & 1.1 \\
Surgery visit type & & 63.9 \\
Outpatient & 34,285 & 36.1 \\
Inpatient & 19,347 & \\
\hline
\end{tabular}

*Indicates that both laparoscopic and open procedures were coded in claims database.

Table 2: Prevalence of comorbidities in the study population.

\begin{tabular}{lcc}
\hline Comorbidity & $\mathbf{n}$ & $\mathbf{\%}$ \\
\hline Hypertension & 18,324 & 34.2 \\
Hyperlipidemia & 16,436 & 30.7 \\
GERD / hiatal hernia & 13,465 & 25.1 \\
Diabetes mellitus & 7,354 & 13.7 \\
Angina / chronic IHD & 4,065 & 7.6 \\
Sleep apnea & 3,064 & 5.7 \\
Heart failure & 1,217 & 2.3 \\
MI / acute IHD & 1,136 & 2.1 \\
Hypertensive heart disease & 1,061 & 2.0 \\
Cirrhosis of liver or bile ducts & 283 & 0.5
\end{tabular}


Table 3: 30-day health care utilization.

\begin{tabular}{|lccc|}
\hline Visit Type & $\begin{array}{c}\text { Number of } \\
\text { Visits }\end{array}$ & $\begin{array}{c}\text { Number of } \\
\text { Patients }\end{array}$ & \% of Cohort \\
\hline ED visits & 4,523 & 3,538 & 6.6 \\
Inpatient readmissions & & 4,103 & 7.7 \\
0 days & & 2,461 & 60.0 \\
1-2 days & 677 & 16.5 \\
3-5 days & & 583 & 14.2 \\
6-10 days & & 214 & 5.2 \\
11+ days & & 168 & 4.1 \\
\hline
\end{tabular}

Table 4: ICD-9 codes and corresponding diagnoses for 30-day readmissions.

\begin{tabular}{llcc} 
ICD-9 & Corresponding Diagnosis & n & \% \\
\hline 789.00 & Abdominal pain; unspecified site & 700 & 7.6 \\
786.50 & Chest pain NOS* & 223 & 2.4 \\
789.01 & Abdominal pain; right upper quadrant & 217 & 2.4 \\
997.4 & Digestive system complications & 212 & 2.3 \\
574.50 & Choledocholithiasis NOS & 205 & 2.2 \\
577.0 & Acute pancreatitis & 190 & 2.1 \\
574.10 & Calculus of gallbladder with other cholecystitis; without & 164 & 1.8 \\
& mention of obstruction & & \\
576.8 & Other specified disorders of the biliary tract & 152 & 1.7 \\
789.07 & Abdominal pain, generalized & 146 & 1.6 \\
787.01 & Nausea with vomiting & 145 & 1.6 \\
\hline
\end{tabular}

*NOS: Not otherwise specified

Table 5: Univariate analysis of 30-day resource utilization stratified by sex.

\begin{tabular}{lccccc}
\hline & \multicolumn{2}{c}{ Female } & \multicolumn{2}{c}{ Male } & N=38,171 \\
& $\mathbf{n}$ & $\mathbf{~ \% ~}$ & $\mathbf{n}$ & $\mathbf{1 5 , 4 6 1}$ & $\begin{array}{c}\text { Chi Square } \\
\text { P value }\end{array}$ \\
Visit to the ED & 2,552 & 6.7 & 986 & 6.4 & 0.1925 \\
30-day readmission & 2,579 & 6.8 & 1,524 & 9.9 & $<.0001$
\end{tabular}

Table 6: Univariate analysis of 30-day resource utilization stratified by comorbidity.

\begin{tabular}{|c|c|c|c|c|c|}
\hline \multicolumn{6}{|l|}{ Heart Failure } \\
\hline & \multicolumn{2}{|c|}{ (+) $\mathrm{N}=1,217$} & \multicolumn{2}{|c|}{$(-) \mathrm{N}=52,415$} & \multirow{2}{*}{$\begin{array}{c}\text { Chi Square } \\
P \text { value }\end{array}$} \\
\hline & n & $\%$ & n & $\%$ & \\
\hline Visit to the ED & 131 & 10.8 & 3,407 & 6.5 & $<.0001$ \\
\hline 30-day readmission & 348 & 28.6 & 3,755 & 7.2 & $<.0001$ \\
\hline \multicolumn{6}{|c|}{ Angina / Chronic IHD } \\
\hline & \multicolumn{2}{|c|}{$(+) \mathrm{N}=4,065$} & \multicolumn{2}{|c|}{ (-) $N=49,567$} & Chi Square \\
\hline & $\mathbf{n}$ & $\%$ & n & $\%$ & $P$ value \\
\hline Visit to the ED & 344 & 8.5 & 3,194 & 6.4 & $<.0001$ \\
\hline 30-day readmission & 740 & 18.2 & 3,363 & 6.8 & $<.0001$ \\
\hline
\end{tabular}


GERD / Hiatal Hernia

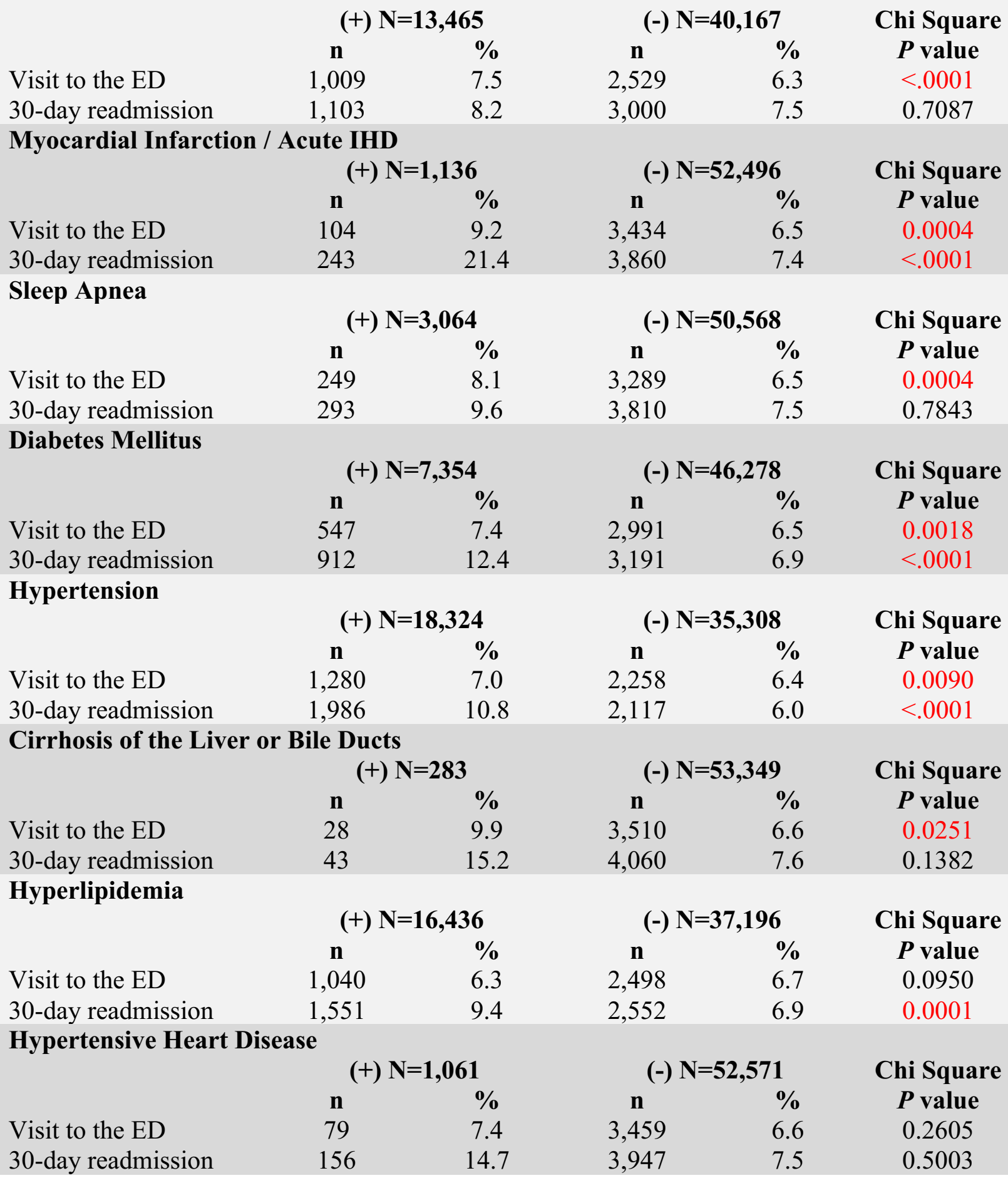

Table 7: Multivariable odds ratios for 30-day readmissions.

\section{Predictor}

Female

Region (Reference: Midwest):

\section{Odds Ratio 95\% Wald}

0.885

0.823

\section{Confidence Limit}

s
Chi Square $P$-Value 0.0008 


\begin{tabular}{|c|c|c|c|c|}
\hline Northeast & 0.905 & 0.811 & 1.010 & $<.0001$ \\
\hline South & 0.885 & 0.809 & 0.969 & \\
\hline West & 0.969 & 0.862 & 1.090 & \\
\hline \multicolumn{5}{|l|}{ Age Group (Reference: 25-34) } \\
\hline$<25$ & 1.347 & 1.131 & 1.605 & $<.0001$ \\
\hline $35-44$ & 0.993 & 0.872 & 1.130 & \\
\hline $45-54$ & 1.061 & 0.935 & 1.204 & \\
\hline $55-64$ & 1.287 & 1.131 & 1.465 & \\
\hline $65-74$ & 2.003 & 1.730 & 2.317 & \\
\hline $75+$ & 4.277 & 3.717 & 4.922 & \\
\hline \multicolumn{5}{|l|}{ Baseline Comorbidities: } \\
\hline Heart Failure & 2.078 & 1.795 & 2.406 & $<.0001$ \\
\hline $\begin{array}{l}\text { Cirrhosis of Liver or Bile } \\
\text { Ducts }\end{array}$ & 1.640 & 1.164 & 2.312 & 0.0047 \\
\hline MI / Acute IHD & 1.463 & 1.236 & 1.733 & $<.0001$ \\
\hline Angina / Chronic IHD & 1.300 & 1.162 & 1.454 & $<.0001$ \\
\hline Diabetes & 1.293 & 1.184 & 1.413 & $<.0001$ \\
\hline Hypertensive Heart Disease & 1.244 & 1.035 & 1.495 & 0.0201 \\
\hline Hypertension & 1.188 & 1.097 & 1.287 & $<.0001$ \\
\hline Hyperlipidemia & 0.867 & 0.801 & 0.938 & 0.0004 \\
\hline
\end{tabular}

Predictors that were not statistically significant: GERD and sleep apnea. 


\section{APPENDICES}

Appendix 1: ICD-9 codes and CPT codes used to identify cholecystectomy procedures. ICD-9

51.22 Cholecystectomy

51.23 Laparoscopic cholecystectomy

CPT

47600 Cholecystectomy

47610 Cholecystectomy with exploration of common duct

47605 Cholecystectomy; with cholangiography

47562 Laparoscopic cholecystectomy

47563 Laparoscopic cholecystectomy with cholangiography

47564 Laparoscopic cholecystectomy with exploration of common duct

Appendix 2: Detailed univariate analysis of 30-day resource utilization stratified by sex.

\begin{tabular}{lccccc}
\hline & \multicolumn{2}{c}{$\begin{array}{c}\text { Female } \\
\mathbf{N = 3 8 , 1 7 1}\end{array}$} & \multicolumn{2}{c}{ Male } & \\
& $\mathbf{n}$ & $\mathbf{0}$ & $\mathbf{1 5 , 4 6 1}$ & $\mathbf{n}$ & $\begin{array}{c}\text { Chi Square } \\
\boldsymbol{P} \text { value }\end{array}$ \\
\hline Visit to the ED & 2,552 & 6.7 & 986 & 6.4 & 0.1925 \\
Number of ED visits & & & & & \\
None & 35,619 & 93.3 & 14,475 & 93.6 & \\
1 visit & 2,018 & 5.3 & 806 & 5.2 & \\
2 visits & 393 & 1.0 & 137 & 0.9 & \\
3 visits & 141 & 0.4 & 43 & 0.3 & \\
\hline 30-day readmission & 2,579 & 6.8 & 1,524 & 9.9 & $<.0001$ \\
Inpatient total LOS & & & & & \\
0 days & 1,501 & 3.9 & 960 & 6.2 & \\
1-2 days & 469 & 1.2 & 208 & 1.3 & \\
3-5 days & 378 & 1.0 & 205 & 1.3 & \\
6-10 days & 132 & 0.3 & 82 & 0.5 & \\
11 days & 99 & 0.3 & 69 & 0.4 & \\
\hline
\end{tabular}

Appendix 3: Detailed univariate analysis of 30-day resource utilization stratified by comorbidity.

\begin{tabular}{lccccc}
\hline Heart Failure & \multicolumn{2}{c}{$\mathbf{( + )} \mathbf{N = 1 , 2 1 7}$} & \multicolumn{2}{c}{$\mathbf{( - )} \mathbf{N}=\mathbf{5 2 , 4 1 5}$} & $\begin{array}{c}\text { Chi Square } \\
\boldsymbol{P} \text { value }\end{array}$ \\
\hline Visit to the ED & $\mathbf{n}$ & $\mathbf{\%}$ & $\mathbf{n}$ & $\mathbf{\%}$ & $<.0001$ \\
Number of ED visits & 131 & 10.8 & 3,407 & 6.5 & \\
$\quad$ None & 1,086 & 89.2 & 49,008 & 93.5 & \\
1 visit & 92 & 7.6 & 2,732 & 5.2 & \\
2 visits & 22 & 1.8 & 508 & 1.0 & \\
$3^{+}$visits & 17 & 1.4 & 167 & 0.3 & \\
\hline
\end{tabular}




\begin{tabular}{|c|c|c|c|c|c|}
\hline 30-day readmission & 348 & 28.6 & 3,755 & 7.2 & $<.0001$ \\
\hline \multicolumn{6}{|l|}{ Inpatient total LOS } \\
\hline 0 days & 256 & 21.0 & 2,205 & 4.2 & \\
\hline 1-2 days & 34 & 2.8 & 643 & 1.2 & \\
\hline 3-5 days & 24 & 2.0 & 559 & 1.1 & \\
\hline 6-10 days & 12 & 1.0 & 202 & 0.4 & \\
\hline $11^{+}$days & 22 & 1.8 & 146 & 0.3 & \\
\hline \multicolumn{6}{|c|}{ Angina / Chronic IHD } \\
\hline & \multicolumn{2}{|c|}{$(+) \mathrm{N}=4,065$} & \multicolumn{2}{|c|}{$(-) N=49,567$} & Chi Square \\
\hline & n & $\%$ & n & $\%$ & $P$ value \\
\hline Visit to the ED & 344 & 8.5 & 3,194 & 6.4 & $<.0001$ \\
\hline \multicolumn{6}{|l|}{ Number of ED visits } \\
\hline None & 3,721 & 91.5 & 46,373 & 93.6 & \\
\hline 1 visit & 265 & 6.5 & 2,559 & 5.2 & \\
\hline 2 visits & 58 & 1.4 & 472 & 1.0 & \\
\hline $3^{+}$visits & 21 & 0.5 & 163 & 0.3 & \\
\hline 30-day readmission & 740 & 18.2 & 3,363 & 6.8 & $<.0001$ \\
\hline \multicolumn{6}{|l|}{ Inpatient total LOS } \\
\hline 0 days & 540 & 13.3 & 1,921 & 3.9 & \\
\hline 1-2 days & 77 & 1.9 & 600 & 1.2 & \\
\hline 3-5 days & 58 & 1.4 & 525 & 1.1 & \\
\hline 6-10 days & 26 & 0.6 & 188 & 0.4 & \\
\hline $11^{+}$days & 39 & 1.0 & 129 & 0.3 & \\
\hline
\end{tabular}

\section{GERD / Hiatal Hernia}

\begin{tabular}{|c|c|c|c|c|c|}
\hline & \multicolumn{2}{|c|}{$(+) \mathrm{N}=13,465$} & \multicolumn{2}{|c|}{$(-) N=40,167$} & \multirow{2}{*}{$\begin{array}{c}\text { Chi Square } \\
P \text { value } \\
\end{array}$} \\
\hline & n & $\%$ & $\mathbf{n}$ & $\%$ & \\
\hline Visit to the ED & 1,009 & 7.5 & 2,529 & 6.3 & $<.0001$ \\
\hline \multicolumn{6}{|l|}{ Number of ED visits } \\
\hline None & 12,456 & 92.5 & 37,638 & 93.7 & \\
\hline 1 visit & 775 & 5.8 & 2,049 & 5.1 & \\
\hline 2 visits & 164 & 1.2 & 366 & 0.9 & \\
\hline $3^{+}$visits & 70 & 0.5 & 114 & 0.3 & \\
\hline 30-day readmission & 1,103 & 8.2 & 3,000 & 7.5 & 0.7087 \\
\hline \multicolumn{6}{|l|}{ Inpatient total LOS } \\
\hline 0 days & 676 & 5.0 & 1,785 & 4.4 & \\
\hline 1-2 days & 169 & 1.3 & 508 & 1.3 & \\
\hline 3-5 days & 153 & 1.1 & 430 & 1.1 & \\
\hline 6-10 days & 61 & 0.5 & 153 & 0.4 & \\
\hline $11^{+}$days & 44 & 0.3 & 124 & 0.3 & \\
\hline \multicolumn{6}{|l|}{ MI / Acute IHD } \\
\hline & \multicolumn{2}{|c|}{$(+) \mathrm{N}=1,136$} & \multicolumn{2}{|c|}{$(-) \mathrm{N}=52,496$} & Chi Square \\
\hline & n & $\%$ & n & $\%$ & $P$ value \\
\hline Visit to the ED & 104 & 9.2 & 3,434 & 6.5 & 0.0004 \\
\hline \multicolumn{6}{|l|}{ Number of ED visits } \\
\hline None & 1,032 & 90.8 & 49,062 & 93.5 & \\
\hline 1 visit & 80 & 7.0 & 2,744 & 5.2 & \\
\hline
\end{tabular}




\begin{tabular}{cccccc}
2 visits & 17 & 1.5 & 513 & 1.0 & \\
$3^{+}$visits & 7 & 0.6 & 177 & 0.3 & $<.0001$ \\
\hline 30-day readmission & 243 & 21.4 & 3,860 & 7.4 & \\
Inpatient total LOS & & & & & \\
0 days & 181 & 15.9 & 2,280 & 4.3 & \\
1-2 days & 22 & 1.9 & 655 & 1.2 & \\
3-5 days & 21 & 1.8 & 562 & 1.1 & \\
6-10 days & 10 & 0.9 & 204 & 0.4 & \\
$11^{+}$days & 9 & 0.8 & 159 & 0.3 & \\
\hline
\end{tabular}

\begin{tabular}{lccccc}
\hline Sleep Apnea & \multicolumn{2}{c}{$\mathbf{( + )} \mathbf{N}=\mathbf{3 , 0 6 4}$} & \multicolumn{2}{c}{$\mathbf{( - )} \mathbf{N}=\mathbf{5 0 , 5 6 8}$} & $\begin{array}{c}\text { Chi Square } \\
\boldsymbol{P} \text { value }\end{array}$ \\
& $\mathbf{n}$ & $\mathbf{\%}$ & $\mathbf{n}$ & $\mathbf{\%}$ & 0.0004 \\
\hline Visit to the ED & 249 & 8.1 & 3,289 & 6.5 & \\
Number of ED visits & & & & & \\
None & 2,815 & 91.9 & 47,279 & 93.5 & \\
1 visit & 197 & 6.4 & 2,627 & 5.2 & \\
2 visits & 34 & 1.1 & 496 & 1.0 & \\
3 $^{+}$visits & 18 & 0.6 & 166 & 0.3 & \\
\hline 30-day readmission & 293 & 9.6 & 3,810 & 7.5 & 0.7843 \\
Inpatient total LOS & & & & & \\
0 days & 179 & 5.8 & 2,282 & 4.5 & \\
1-2 days & 53 & 1.7 & 624 & 1.2 & \\
3-5 days & 36 & 1.2 & 547 & 1.1 & \\
6-10 days & 13 & 0.4 & 201 & 0.4 & \\
1 ${ }^{+}$days & 12 & 0.4 & 156 & 0.3 & \\
\hline
\end{tabular}

\section{Diabetes Mellitus}

(+) $\mathrm{N}=7,354$

\begin{tabular}{lccccc} 
& n & \% & n & \% & $\boldsymbol{P}$ value \\
\hline Visit to the ED & 547 & 7.4 & 2,991 & 6.5 & 0.0018
\end{tabular}

Number of ED visits

None $\quad 6,807$

1 visit

431

2 visits

77

$3^{+}$visits

30-day readmission

Inpatient total LOS

$\begin{array}{lc}0 \text { days } & 577 \\ 1-2 \text { days } & 130 \\ 3-5 \text { days } & 116 \\ 6-10 \text { days } & 47 \\ 11^{+} \text {days } & 42\end{array}$

\section{Hypertension}

39

912

92.6

43,287

2,393

93.5

5.9

453

5.2

1.0

145

1.0

0.5

3,191

0.3

6.9

$<.0001$

$\begin{array}{llcl}577 & 7.8 & 1,884 & 4.1 \\ 130 & 1.8 & 547 & 1.2 \\ 116 & 1.6 & 467 & 1.0 \\ 47 & 0.6 & 167 & 0.4 \\ 42 & 0.6 & 126 & 0.3\end{array}$

\section{(+) $\mathrm{N}=18,324$}

(-) $\mathrm{N}=\mathbf{3 5 , 3 0 8}$

Chi Square

Visit to the ED

$\begin{array}{ll}\text { n } & \text { \% } \\ 1,280 & 7.0\end{array}$

Number of ED visits

2,258

6.4




\begin{tabular}{|cccccc}
\hline None & 17,044 & 93.0 & 33,050 & 93.6 & \\
1 visit & 1,012 & 5.5 & 1,812 & 5.1 & \\
2 visits & 181 & 1.0 & 349 & 1.0 & \\
3 $^{+}$visits & 87 & 0.5 & 97 & 0.3 & $<.0001$ \\
\hline 30-day readmission & 1,986 & 10.8 & 2,117 & 6.0 & \\
Inpatient total LOS & & & & & \\
0 days & 1,283 & 7.0 & 1,178 & 3.3 & \\
1-2 days & 413 & 2.3 & 413 & 1.2 & \\
3-5 days & 335 & 1.8 & 335 & 0.9 & \\
6-10 days & 117 & 0.6 & 117 & 0.3 & \\
11 $1^{+}$days & 74 & 0.4 & 74 & 0.2 & \\
\hline
\end{tabular}

\section{Cirrhosis of the Liver or Bile Ducts}

\begin{tabular}{lccccc} 
& $\mathbf{n}$ & $\mathbf{( + )} \mathbf{N}=\mathbf{2 8 3}$ & \multicolumn{2}{c}{$\mathbf{( - )} \mathbf{N}=\mathbf{5 3 , 3 4 9}$} & $\begin{array}{c}\text { Chi Square } \\
\boldsymbol{P} \text { value }\end{array}$ \\
\hline Visit to the ED & 28 & 9.9 & 3,510 & 6.6 & 0.0251 \\
Number of ED visits & & & & & \\
$\quad$ None & 255 & 90.1 & 49,839 & 93.4 & \\
1 visit & 19 & 6.7 & 2,805 & 5.3 & \\
2 visits & 7 & 2.5 & 523 & 1.0 & \\
3 $^{+}$visits & 2 & 0.7 & 182 & 0.3 & \\
\hline 30-day readmission & 43 & 15.2 & 4,060 & 7.6 & 0.1382 \\
Inpatient total LOS & & & & & \\
0 days & 27 & 9.5 & 2,434 & 4.6 & \\
1-2 days & 3 & 1.1 & 674 & 1.3 & \\
3-5 days & 5 & 1.8 & 578 & 1.1 & \\
6-10 days & 5 & 1.8 & 209 & 0.4 & \\
1 $1^{+}$days & 3 & 1.1 & 165 & 0.3 & \\
\hline
\end{tabular}

\section{Hyperlipidemia}

(+) $\mathrm{N}=\mathbf{1 6 , 4 3 6} \quad(-) \mathrm{N}=\mathbf{3 7 , 1 9 6}$

Chi Square

\begin{tabular}{cccccc} 
& $\mathbf{n}$ & $\mathbf{\%}$ & $\mathbf{n}$ & $\mathbf{\%}$ & $\boldsymbol{P}$ value \\
\hline Visit to the ED & 1,040 & 6.3 & 2,498 & 6.7 & 0.0950
\end{tabular}

Number of ED visits

\begin{tabular}{|c|c|c|c|c|c|}
\hline None & 15,396 & 93.7 & 34,698 & 93.3 & \\
\hline 1 visit & 836 & 5.1 & 1,988 & 5.3 & \\
\hline 2 visits & 150 & 0.9 & 380 & 1.0 & \\
\hline $3^{+}$visits & 54 & 0.3 & 130 & 0.3 & \\
\hline $\begin{array}{l}\text { readmission } \\
\text { nt total LOS }\end{array}$ & 1,551 & 9.4 & 2,552 & 6.9 & 0.0001 \\
\hline 0 days & 1,001 & 6.1 & 1,460 & 3.9 & \\
\hline 1-2 days & 218 & 1.3 & 459 & 1.2 & \\
\hline 3-5 days & 193 & 1.2 & 390 & 1.0 & \\
\hline 6-10 days & 78 & 0.5 & 136 & 0.4 & \\
\hline $11^{+}$days & 61 & 0.4 & 107 & 0.3 & \\
\hline
\end{tabular}

\section{Hypertensive Heart Disease}

$$
\text { (+) } \mathrm{N}=1,061
$$

n

$\%$

$(-) \mathrm{N}=\mathbf{5 2 , 5 7 1}$

Chi Square $P$ value 


\begin{tabular}{lccccc} 
Visit to the ED & 79 & 7.4 & 3,459 & 6.6 & 0.2605 \\
Number of ED visits & & & & & \\
None & 982 & 92.6 & 49,112 & 93.4 & \\
1 visit & 61 & 5.7 & 2,763 & 5.3 & \\
2 visits & 15 & 1.4 & 515 & 1.0 & \\
3 $^{+}$visits & 3 & 0.3 & 181 & 0.3 & \\
\hline 30-day readmission & 156 & 14.7 & 3,947 & 7.5 & 0.5003 \\
Inpatient total LOS & & & & & \\
0 days & 94 & 8.9 & 2,367 & 4.5 & \\
1-2 days & 22 & 2.1 & 655 & 1.2 & \\
3-5 days & 20 & 1.9 & 563 & 1.1 & \\
6-10 days & 10 & 0.9 & 204 & 0.4 & \\
$11^{+}$days & 10 & 0.9 & 158 & 0.3 & \\
\hline
\end{tabular}

Appendix 4: Multivariable odds ratios for 30-day readmissions with same-day discharge.

\begin{tabular}{|c|c|c|c|c|}
\hline Predictor & \multirow[t]{2}{*}{ Odds Ratio } & \multicolumn{2}{|c|}{$\begin{array}{c}\text { 95\% Wald } \\
\text { Confidence Limits }\end{array}$} & \multirow{2}{*}{$\begin{array}{c}\text { Chi Square } \\
\text { P-Value } \\
<.0001\end{array}$} \\
\hline $\begin{array}{l}\text { Age Group (Reference: } 25-34 \\
\text { years) }\end{array}$ & & & & \\
\hline$<25$ & 1.405 & 1.102 & 1.792 & \\
\hline $35-44$ & 1.012 & 0.843 & 1.216 & \\
\hline $45-54$ & 1.130 & 0.947 & 1.349 & \\
\hline $55-64$ & 1.420 & 1.188 & 1.698 & \\
\hline $65-74$ & 3.192 & 2.646 & 3.850 & \\
\hline $75+$ & 7.772 & 6.498 & 9.297 & \\
\hline \multicolumn{5}{|l|}{ Baseline Comorbidities: } \\
\hline Angina / Chronic IHD & 1.363 & 1.197 & 1.553 & $<.0001$ \\
\hline $\begin{array}{l}\text { Cirrhosis of the Liver or } \\
\text { Bile Ducts }\end{array}$ & 1.634 & 1.066 & 2.504 & 0.0241 \\
\hline Diabetes & 1.226 & 1.099 & 1.368 & 0.0003 \\
\hline Heart Failure & 1.964 & 1.662 & 2.322 & $<.0001$ \\
\hline Hyperlipidemia & 0.884 & 0.801 & 0.975 & 0.0138 \\
\hline Hypertension & 1.122 & 1.013 & 1.242 & 0.0269 \\
\hline MI / Acute IHD & 1.564 & 1.290 & 1.897 & $<.0001$ \\
\hline
\end{tabular}

Predictors that were not significant: Sex, region, GERD, sleep apnea, hypertensive heart disease

Appendix 5: Multivariable odds ratios for 30-day overnight readmissions.

\begin{tabular}{lcccc}
\hline Predictor & Odds Ratio & \multicolumn{2}{c}{$\mathbf{9 5 \%}$ Wald } & \multicolumn{2}{c}{ Chi Square } \\
& 0.854 & 0.767 & 0.951 & 0.0040 \\
Female & & & & \\
Region (Reference: Midwest): & 0.963 & 0.820 & 1.131 & 0.0056 \\
$\quad$ Northeast & 0.819 & 0.715 & 0.937 &
\end{tabular}




$\begin{array}{lllll}\text { West } & 0.968 & 0.814 & 1.151 & \\ \text { Baseline Comorbidities: } & & & & \\ \text { Angina / Chronic IHD } & 1.207 & 1.012 & 1.439 & 0.0360 \\ \text { Diabetes } & 1.377 & 1.201 & 1.579 & <.0001 \\ \text { Heart Failure } & 1.874 & 1.475 & 2.381 & <.0001 \\ \text { Hyperlipidemia } & 0.863 & 0.766 & 0.973 & 0.0163 \\ \text { Hypertension } & 1.271 & 1.131 & 1.428 & <.0001 \\ \text { Hypertensive Heart Disease } & 1.580 & 1.207 & 2.069 & 0.0009\end{array}$

Predictors that were not statistically significant: Age, GERD, sleep apnea, acute IHD, and cirrhosis of the liver or bile ducts. 